\title{
Analysis of the Kobe earthquake time series via system identification and fault-detection techniques
}

\author{
S. Bittanti y S. Garatti \\ Dipartimento di Elettronica, Informazione e Bioingegneria \\ Politecnico di Milano, Piazza L. da Vinci, 32, 20133 Milano, Italy. \\ sergio.bittanti@polimi.it \\ simone.garatti@polimi.it
}

\begin{abstract}
The Kobe earthquake was one the most severe earthquakes in Japan in recent years. It occurred on January 16, 1995, at 20:46:49 (UTC) and measured 6.8 on the moment magnitude scale. In this paper, the time series of the unbiased earth ground vertical acceleration collected by a seismograph located at the University of Tasmania, Hobart, Australia, is analyzed. The time series is segmented into three consequent sub-series which represent the normal seismic activity before the arrival of the earthquake, a transition phase, and the arrival of earthquake waves. The analysis is separately performed for each segment. We show that by inspecting the degradation of the prediction performance of the model identified based on the normal seismic activity data set, it is possible to distinguish between the transition phase and normal seismic activity about 200-300 seconds before the beginning of the earthquake phase. Though this does not mean that earthquakes can be forecasted, because of the significant data distortion due to the long distance between the epicenter and the data collection location, nevertheless the achieved result may open up new routes in the study of earthquakes.
\end{abstract}

Key words: seismology, earthquakes, time series prediction, model identification, fault detection.

\section{Análisis de la serie temporal del terremoto de Kobe mediante técnicas de identificación de sistemas y detección de interrupciones}

\author{
RESUMEN
}

El terremoto de Kobe fue uno de los sismos más severos ocurrido en Japón durante los últimos años. Ocurrió el 16 de enero de 1995 a las 20:46:49 (TUC) y alcanzó 6.8 en la escala de magnitud local. En este trabajo se analiza la serie temporal insesgada de la aceleración vertical del terreno registrada por un sismógrafo localizado en la Universidad de Tasmania, en Hobart, Australia. La serie temporal se segmenta en tres sub-series consecutivas que representan la actividad sísmica normal antes de la llegada del terremoto, una transición de fase, y la llegada de las ondas sísmicas. El análisis se realiza de modo separado para cada segmento. Se muestra como por la inspección de la degradación de la capacidad predictora del modelo identificado basado en el conjunto de datos de la actividad sísmica normal, es posible distinguir entre la transición de fase y la actividad sísmica normal en torno a 200-300 segundos antes del comienzo de la fase del terremoto. Aunque esto no significa que los terremotos se pueden predecir, debido a la gran distorsión en los datos debido a la gran distancia al epicentro y a la estación colectora de los datos, sin embargo el resultado alcanzado abre nuevas rutas para el estudio de los terremotos.

Palabras clave: sismología, terremotos, predicción de series temporales, identificación de modelos, detección de interrupciones.

\section{Introduction}

The Kobe earthquake occurred on January 16, 1995, at 20:46:49 (UTC) and measured 6.8 on the moment magnitude scale. It was one of the most severe earthquakes in Japan in recent years.
In this paper, we analyze the time series of the unbiased vertical acceleration in $\mathrm{nm} / \mathrm{s}_{2}$ of the earth ground collected by a seismograph located at the University of Tasmania, Hobart, Australia, over a time window including the arrival of seismic waves generated by the Kobe earthquake. To be precise, the meas- 
urements began at 20:56:51 (UTC), with a sampling time $T=1 \mathrm{~s}$, and lasted for 3000 seconds (about 51 minutes). In the following, the time series will be denoted by $y(t), t=1,2, \ldots, 3000$. See Figure 1 for a plot of $y(t)$.

As is clear from the sudden change of the time series amplitude, the seismic waves show up 1700 seconds after the beginning of data recording, that is, at time 21:25:10 (UTC). The 40 minute delay with respect to the earthquake occurrence is clearly due to the $8600 \mathrm{~km}$ distance between Kobe and Hobart. It results in a propagation speed of about $3580 \mathrm{~m} / \mathrm{s}$, which is quite likely for seismic waves.

Because of the arrival of the seismic waves, visual inspection reveals that the time series cannot be thought of as a realization of a stationary stochastic process (variance at least is time-varying). For this reason, we decided to segment the time series into three parts as shown in Figure 2.
The first segment for $t=1, \ldots, 1200$ is labelled as "normal seismic activity", since seismic waves have not arrived yet, whilst the third segment for $\mathrm{t}=1601, \ldots$, 3000 is labelled as "earthquake" for the very opposite reason. The second segment for $t=1201, \ldots, 1600$, instead, represents a "transition phase" between the normal seismic activity and the earthquake phase. Recalling that the time series is unbiased and hence the mean of $y(t)$ is equal to 0 , the empirical variance calculated over the second segment is

$$
\frac{1}{400} \sum_{t=1201}^{1600} y(t)^{2}=2.5 \cdot 10^{7}\left(\mathrm{~nm} / \mathrm{s}^{2}\right)^{2}
$$

Importantly enough, this variance has the same magnitude as that registered during the normal seismic activity, which is

$$
\frac{1}{1200} \sum_{t=1}^{1200} y(t)^{2}=1.15 \cdot 10^{7}\left(\mathrm{~nm} / \mathrm{s}^{2}\right)^{2}
$$

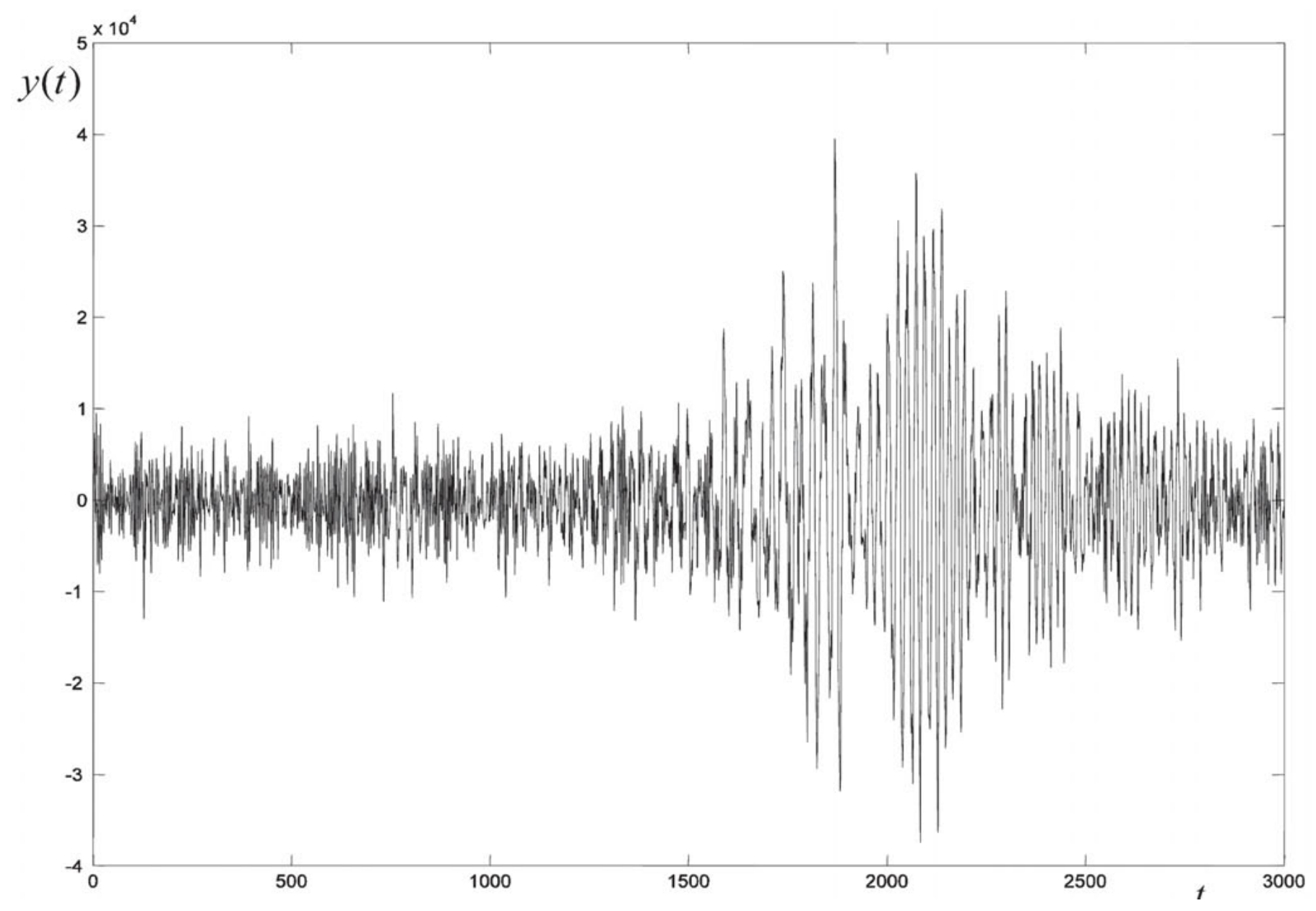

Figure 1. The time series $\mathrm{y}(\mathrm{t})$.

Figura 1. La serie temporal $y(t)$. 


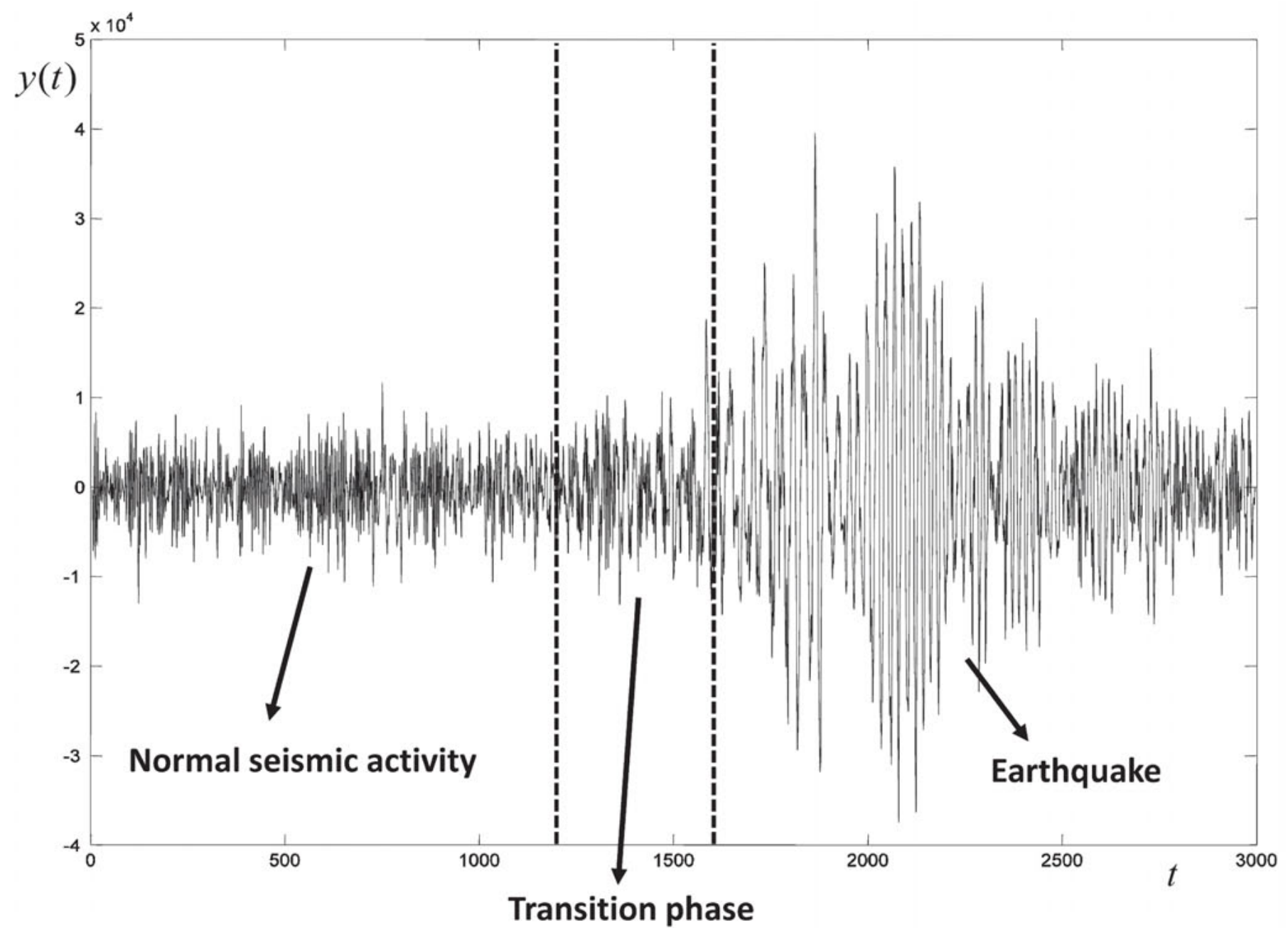

Figure 2. Partition of the time series into three segments.

Figura 2. Partición de la serie temporal en tres segmentos.

Hence, during the transition phase no oscillations with a magnitude different from that of oscillations in the normal seismic activity phase are perceived. During the earthquake segment, instead, the variance is

$$
\frac{1}{1400} \sum_{t=1601}^{3000} y(t)^{2}=1.12 \cdot 10^{8}\left(\mathrm{~nm} / \mathrm{s}^{2}\right)^{2}
$$

which is one order of magnitude bigger than that of the previous segments.

The objective of this paper is to show that, though the empirical variance is the same, the transition phase and the normal seismic activity are radically different in terms of the underlying generation mechanism. In fact, after performing model identification over the normal seismic activity segment, we will show that, by observing the degradation of the model prediction capabilities, it is possible to discern between the normal seismic activity and the transition phase in spite of the lack of variation of the amplitude of oscillations. This opens up the possibility of forecasting the subsequent earthquake phase in the collected data.

The paper is organized as follows. Model identification, including model order selection, of the normal seismic activity segment is discussed in the section Modelling the normal seismic activity segment, while the Model validation section provides some model validation over both the normal seismic activity segment and the earthquake segment. The Analysis of the transition phase via fault detection techniques section applies fault-detection techniques to the transition phase segment and shows that the degradation of the prediction capabilities of the model identified in the Modelling the normal seismic activity segment 
section permits us to discern the transition phase from the normal seismic activity 200-300 seconds before the beginning of the earthquake phase. Finally, some conclusions are drawn in the Conclusions section.

\section{Modelling the normal seismic activity segment}

Non-parametric statistical analysis was first performed, see (Anderson, 1959), (Ljung, 1989), (Brockwell and Davis, 2002), (Stoica and Moses, 2005), and (Bittanti, 2017). Figure 3 displays the periodogram

$$
\hat{\Gamma}_{y}(\omega)=\frac{1}{1200}\left|\sum_{t=1}^{1200} y(t) e^{-j \omega t}\right|^{2}
$$

along with the empirical covariance function

$$
\hat{\gamma}_{y}(\tau)=\frac{1}{1200-\tau} \sum_{i=1}^{1200-\tau} y(i) y(i+\tau)
$$

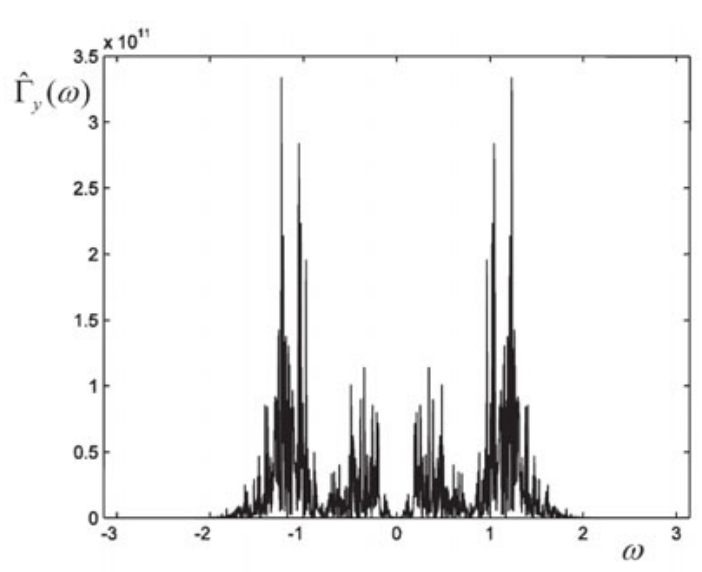

and the partial correlation function parcor( $(\mathrm{k})$ for the time series $y(t)$ over the normal seismic activity segment. parcor $(k)$ was calculated by means of the Durbin-Levinson algorithm, see (Durbin, 1959).

Being $\hat{\gamma}_{\gamma}(\tau)$ and parcor $(k)$ not null after a finite number of time lags, not even approximately, Figure 3 suggests modelling the time series in the normal seismic activity segment as the realization of an ARMA $\left(\mathrm{n}_{\mathrm{a}}, \mathrm{n}_{\mathrm{c}}\right)$ stochastic linear model:

$y(t)=\frac{C(z)}{A(z)} e(t)=\frac{1+c_{1} z^{-1}+\cdots+c_{n_{c}} z^{-n_{c}}}{1+a_{1} z^{-1}+\cdots+a_{n_{s}} z^{-n_{s}}} e(t), \quad e(t) \approx W N\left(0, \lambda^{2}\right)$

( $\mathrm{WN}=$ white noise).

For the fixed model orders $n_{a}, n_{c}$, the model parameters are retrieved by means of standard Prediction Error (PE) methods, (Ljung, 1989), (Sodestrom and Stoica, 1989), (Box et al, 2016), and (Bittanti, 2017). That is, letting $\theta=\left[a_{1} \ldots a_{n a} C_{1} \ldots c_{n c}\right]^{\top}$, the optimal parameter vector is obtained as the minimizer of the empirical prediction error variance:

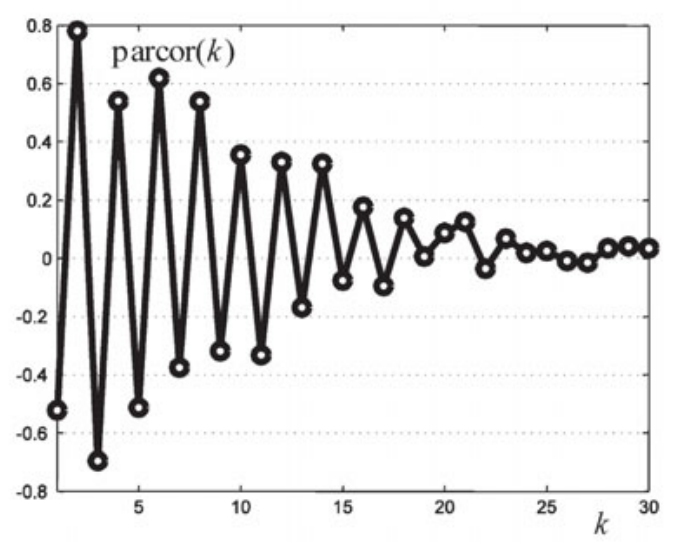

Figure 3. Non-parametric properties of $\gamma(\mathrm{t})$ over the normal seismic activity segment.

Figura 3. Propiedades no-paramétricas de $\gamma(t)$ sobre el segmento de actividad sísmica normal. 


$$
\hat{\theta}_{1200}^{n_{n}, n_{c}}=\arg \min _{\theta} \frac{1}{1200} \sum_{t=1}^{1200}(y(t)-\hat{y}(t \mid t-1, \theta))^{2}
$$

where

$$
y(t \mid t-1, \theta)=\frac{C(z)-A(z)}{C(z)} y(t)
$$

is the 1-step optimal predictor for model in equation (1). The value

$$
\hat{\theta}_{1200}^{n_{a}, n_{c}}
$$

can be actually computed based on classical quasiNewton algorithms, (Ljung, 1989), (Sodestrom and Stoica, 1989), and (Bittanti, 2017).

As for the optimal model orders, we resort to Rissanen's Minimum Description Length (MDL) indicator, (Rissanen, 1978), (Grunwald, 2007), and (Bittanti, 2017). To be precise, we let both $n_{a}$ and $n_{c}$ range from 1 up to 12 , and compute

$$
\hat{\theta}_{1200}^{n_{a}, n_{c}}
$$

for the various $n_{a}$ and $n_{c}$ according to equation (2). For each identified model parameter vector, the MDL indicator is computed as

$$
\begin{aligned}
& \operatorname{MDL}\left(n_{a}, n_{c}\right)=\ln (1200) \frac{n_{a}+n_{c}}{1200}+ \\
& \ln \left(\frac{1}{1200} \sum_{t=1}^{1200}\left(y(t)-\hat{y}\left(t \mid t-1, \theta_{1200}\right)\right)^{2}\right)
\end{aligned}
$$

The optimal $n_{a}, n_{c}$ are those returning the lowest value for MDL.

The actually computed values for MDL are reported in Figure 4, showing that the minimum is achieved for $\mathrm{n}_{\mathrm{a}}=7$ and $\mathrm{n}_{\mathrm{c}}=9$.

The identified model, corresponding to

$$
\hat{\theta}_{1200}^{7,9}
$$

is given by

$$
\begin{gathered}
\begin{array}{c}
A(z)=1-2.5 z^{-1}+2.8 z^{-2}-1.6 z^{-3} \\
+
\end{array} \quad 0.7 z^{-5}-0.6 z^{-6}+0.2 z^{-7} \\
C(z)=1+1.1 z^{-1}-1.6 z^{-2}-1.7 z^{-3}+1.6 z^{-4} \\
+1.2 z^{-5}-1.5 z^{-6}-1.0 z^{-7}+0.6 z^{-8}+0.4 z^{-9} \\
\lambda^{2}=1.59 \cdot 10^{5}\left(\mathrm{~nm} / \mathrm{s}^{2}\right)^{2}
\end{gathered}
$$

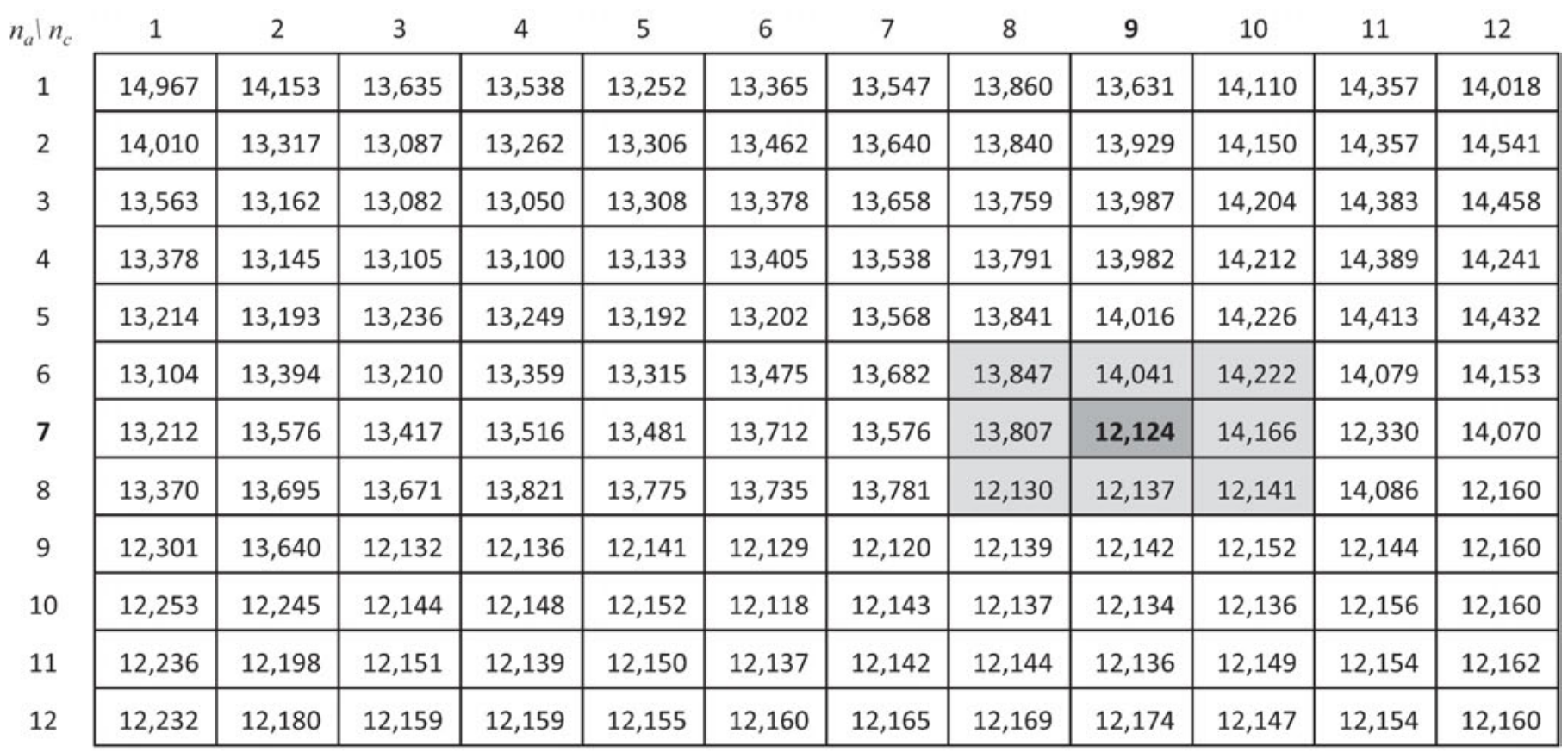

$$
\operatorname{MDL}\left(n_{a}, n_{c}\right)=\ln (N) \frac{n_{a}+n_{c}}{N}+\ln \left(J\left(\hat{\theta}_{1200}^{n_{a}, n_{c}}\right)\right)
$$

Figure 4. $\operatorname{MDL}\left(\mathrm{n}_{\mathrm{a}}, \mathrm{n}_{\mathrm{c}}\right)$ for $\mathrm{n}_{\mathrm{a}}=1, \ldots, 12$ and $\mathrm{n}_{\mathrm{c}}=1, \ldots, 12$.

Figura 4. $M D L\left(n_{a}, n_{c}\right)$ for $n_{a}=1, \ldots, 12$ y $n_{c}=1, \ldots, 12$. 
Figure 5 depicts the spectrum

$$
\Gamma_{y}(\omega)=\frac{\left|C\left(e^{-j \omega}, \theta_{1200}^{7,9}\right)\right|^{2}}{\left|A\left(e^{-j \omega}, \theta_{1200}^{7,9}\right)\right|^{2}} \lambda^{2}
$$

of the ARMA stochastic process generated by (3).

This spectrum is in full agreement with the periodogram in Figure 3. The poles (crosses) and zeros (circles) of (3) are also reported in Figure 5.

\section{Model validation}

As recalled by the saying "the proof of the pudding is in the eating", model validation is performed to test the model capabilities. Based on the model corresponding to (3), the predictor

$$
\hat{y}\left(t \mid t-1, \hat{\theta}_{1200}^{7,9}\right)
$$

can be computed. The left side of Figure 6 depicts $y(t)$ vs.

$$
\hat{y}\left(t \mid t-1, \hat{\theta}_{1200}^{7,9}\right)
$$

over the normal seismic activity segment, i.e. for $t=1$, $\ldots, 1200$. The corresponding prediction error

$$
\varepsilon\left(t \mid t-1, \hat{\theta}_{1200}^{7,9}\right)=y(t)-\hat{y}\left(t \mid t-1, \hat{\theta}_{1200}^{7,9}\right)
$$

has empirical variance equal to

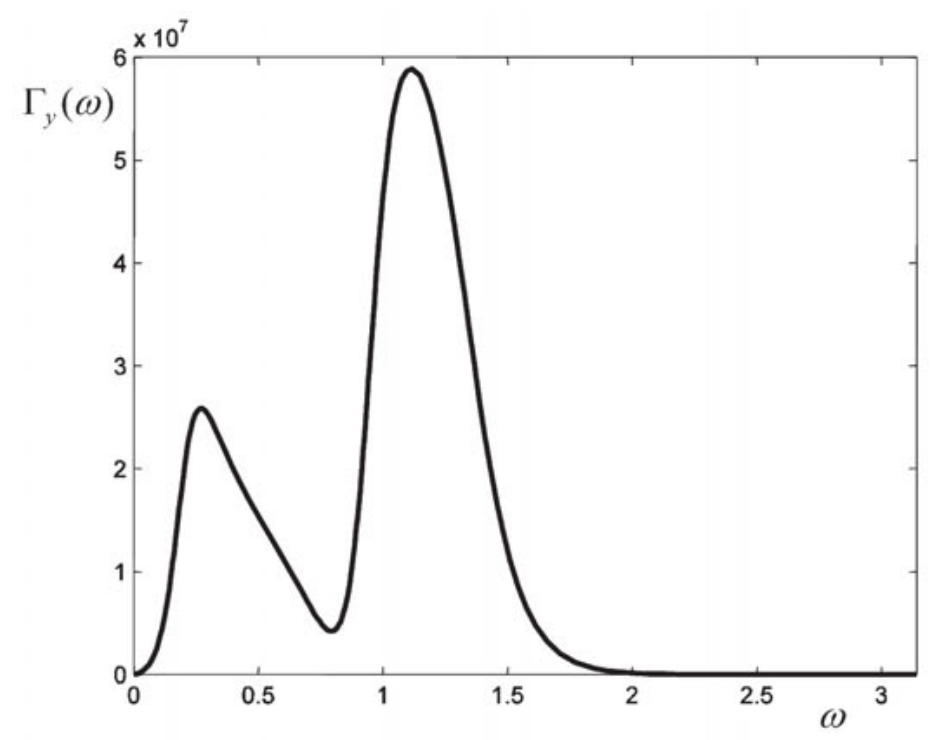

$$
\frac{1}{1200} \sum_{t=1}^{1200} \varepsilon\left(t \mid t-1, \hat{\theta}_{1200}^{7,9}\right)^{2}=\lambda^{2}=1.59 \cdot 10^{5}\left(\mathrm{~nm} / \mathrm{s}^{2}\right)^{2}
$$

which is two order of magnitude smaller than the empirical variance of $\mathrm{y}(\mathrm{t})$.

The right side of Figure 6 depicts the correlation coefficient

$$
\hat{\rho}_{\varepsilon}(\tau)=\frac{\hat{\gamma}_{\varepsilon}(\tau)}{\hat{\gamma}_{\varepsilon}(0)}
$$

along with the $95 \%$ confidence interval for the Anderson's whiteness test, (Anderson, 1959), (Ljung, 1989), and (Box et al, 2016). Since all the displayed $\hat{\rho}_{\varepsilon}(\tau), \tau=1, \ldots, 24$, are within the confidence interval, the whiteness test is passed and

$$
\varepsilon\left(t \mid t-1, \hat{\theta}_{1200}^{7,9}\right)
$$

can be presumed to be a white noise. Thus, the conclusion is drawn that the identified model is an accurate and complete descriptor of the data generation mechanism underlying the registered normal seismic activity.

We then checked whether the obtained model is also a good descriptor of the earthquake segment, for $t=1601, \ldots, 3000$, or not.

A negative answer is quite immediate because even both the plot of $y(t), t=1601, \ldots, 3000$, (Figure 7, left) and that of the corresponding periodogram (Fig.7, right) present features that are remarkably different from those of the same plots during normal

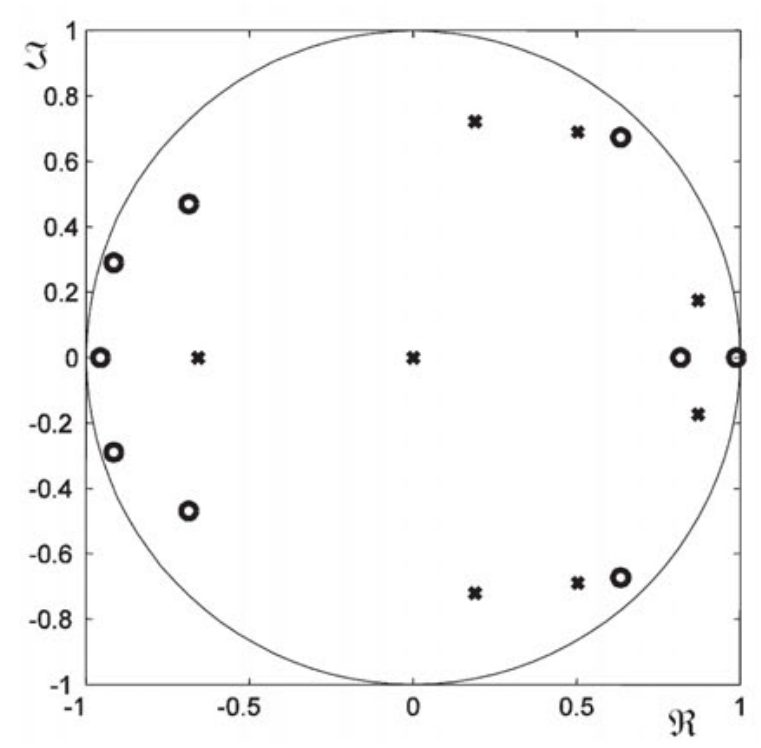

Figure 5. Spectrum and poles and zeros of the identified stochastic model. Figura 5. Espectro, polos y ceros del modelo estocástico identificado. 

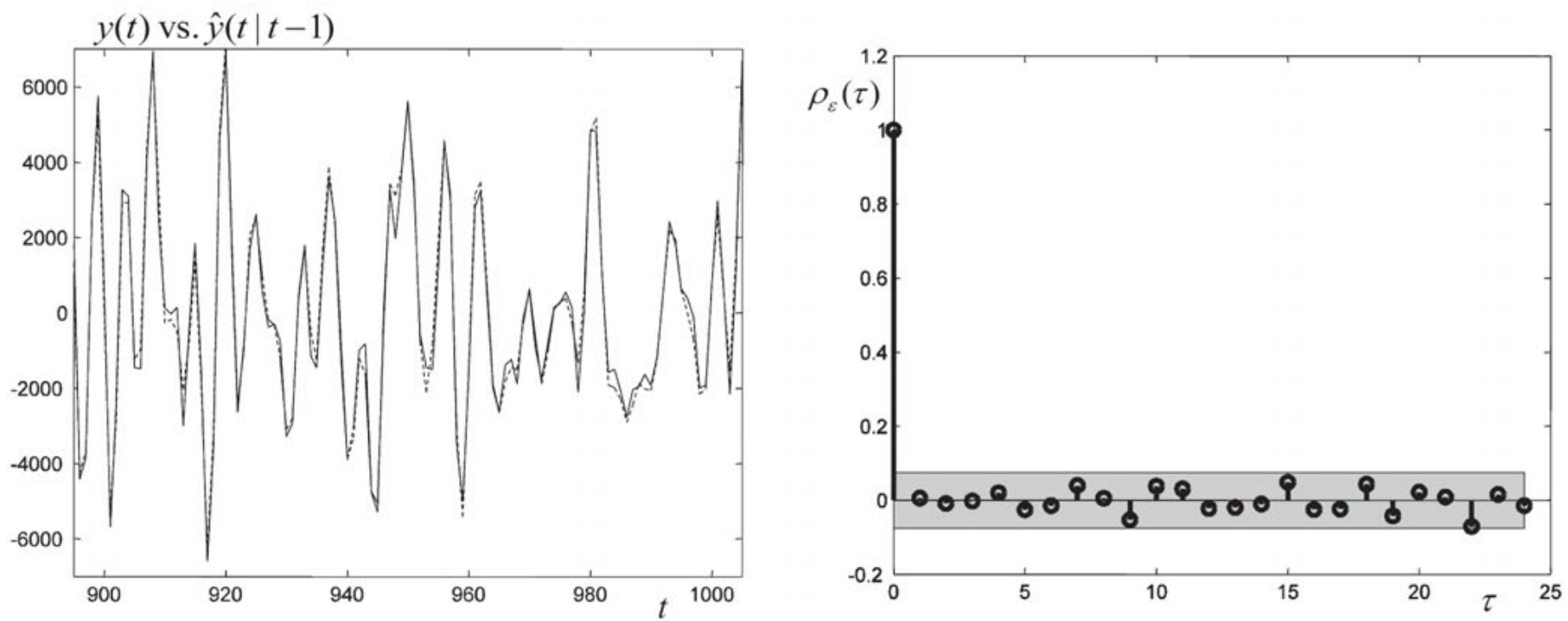

Figure 6. Left: $y(t)$ (dashed line) vs. $\hat{y}\left(t \mid t-1, \hat{\theta}_{1200}^{7,9}\right.$ (continuous line). Right: Anderson's whiteness test for the prediction error. Figura 6. Izquierda: $y(t)$ (línea discontínua) frente a $\hat{y}\left(t \mid t-1, \hat{\theta}_{1200}^{7,9}\right)$. Derecha: test de aleatoriedad de Anderson para el error de predicción.
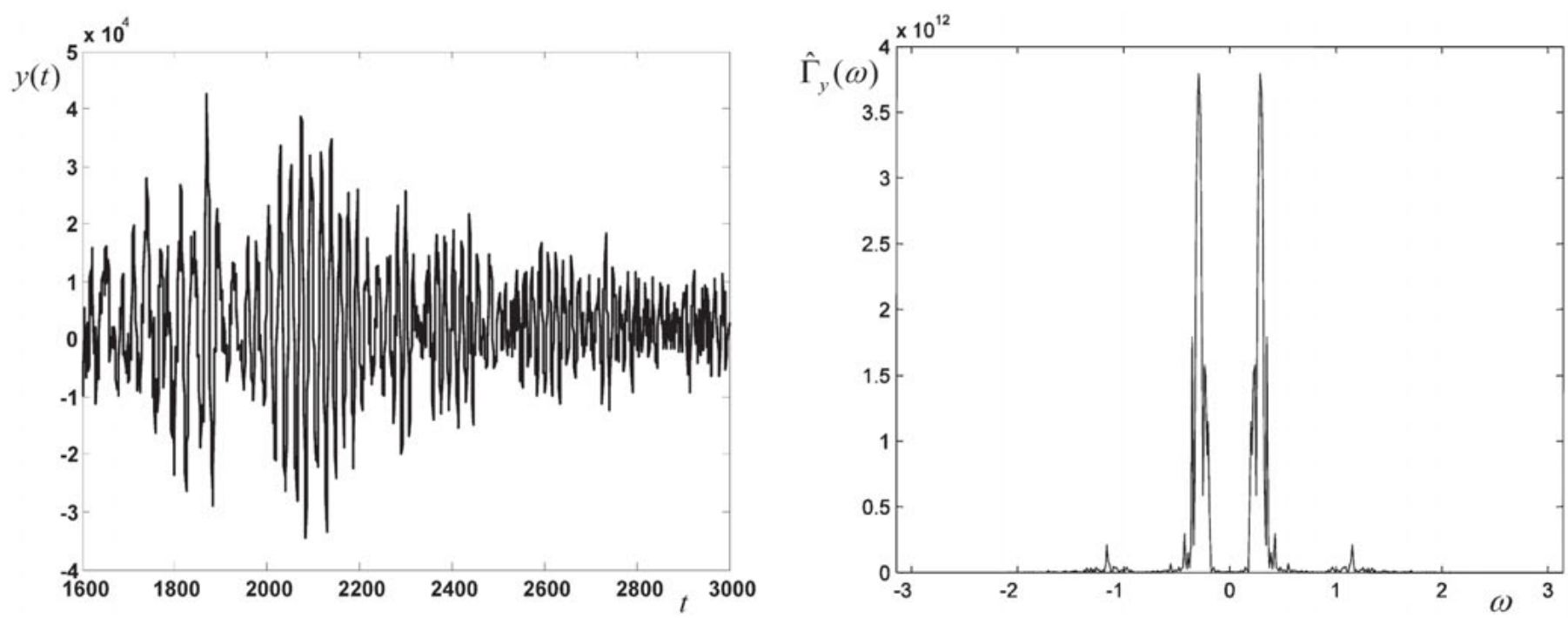

Figure 7. The earthquake phase segment (left) along with the corresponding periodogram (right).

Figura 7. El segmento de la fase del terremoto (izquierda) así como su periodograma correspondiente (derecha).

seismic activity. Anyway, by applying the whiteness test to the prediction error

$$
\varepsilon\left(t \mid t-1, \hat{\theta}_{1200}^{7,9}\right)
$$

for $t=1601, \ldots, 3000$, the result shown in Figure 8 is obtained.
This clearly reveals that the model corresponding to (3) is not apt for describing the earthquake phase and that earthquakes differ from the normal seismic activity not only because of the amplitude of oscillations but also because a change of the underlying data generation mechanism. 


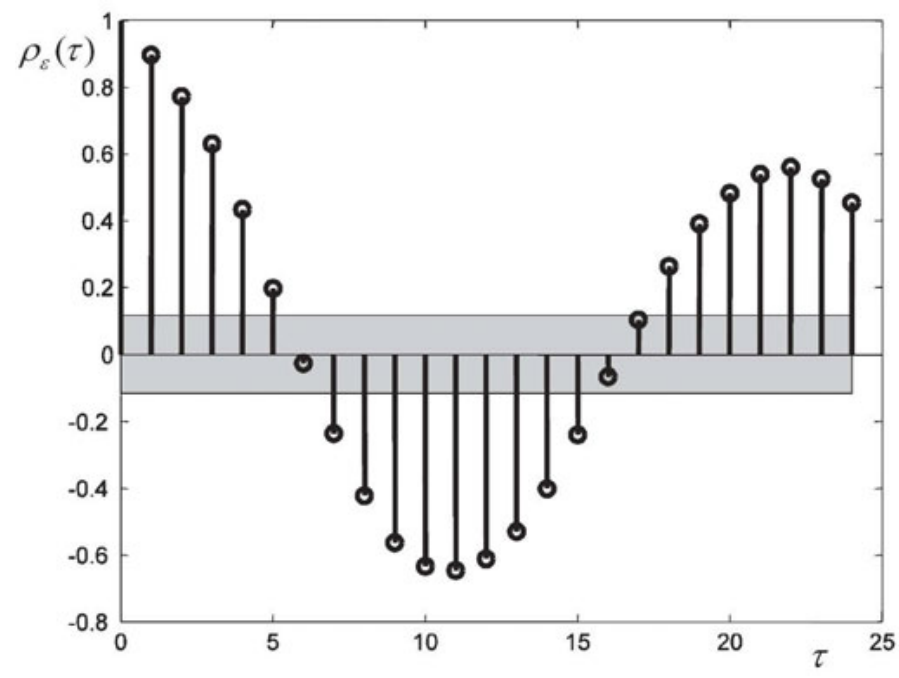

Figure 8. Whiteness test for the earthquake phase.

Figura 8. Test de aleatoriedad para la fase del terremoto.

\section{Analysis of the transition phase via fault detection techniques}

Given the results in the Model validation section, a method for forecasting the earthquake phase in the collected data is developed based on the degradation of the prediction capabilities of model (3).
The idea is borrowed from the field of fault detection/fault diagnosis, (Hwang et al, 2010), and is easily explained as follows.

We have already seen that model (3), which, we may recall, has been identified during the normal seismic activity phase, is able to discern between the normal seismic activity and the earthquake phase, because in the first case the returned prediction error is white (the whiteness test is passed) whilst in the second case it is not (the whiteness test is failed). As is clear, this property is not very useful because the two segments are discerned by means of the variation of the amplitude of oscillations (as pointed out in the introduction, there is a variation of one order of magnitude between the empirical variance of the time series in the first and in the third segment). The transition phase, instead, presents oscillations whose amplitude is close to that of oscillations in the normal seismic activity. The question is whether the use of model (3) permits us to discern the first and the second segments or not.

To answer this question, we further divided the transition phase segment into the four 100 seconds long time windows as shown in Figure 9, and performed the whiteness test to the prediction error sequence

$$
\varepsilon\left(t \mid t-1, \hat{\theta}_{1200}^{7,9}\right)
$$

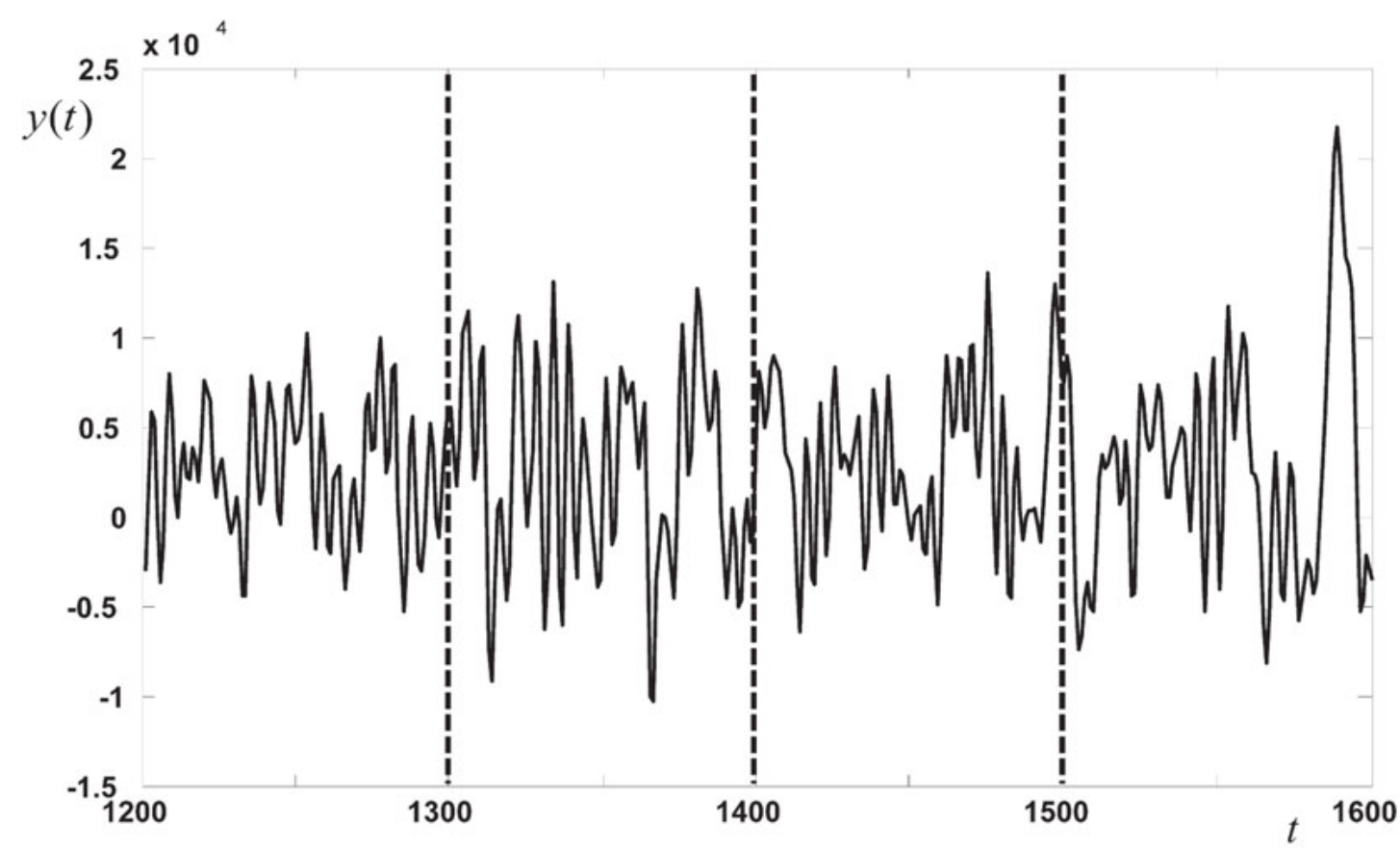

Figure 9. The transition phase segment and its further partition.

Figura 9. El segmento de transición de fase y su partición posterior. 

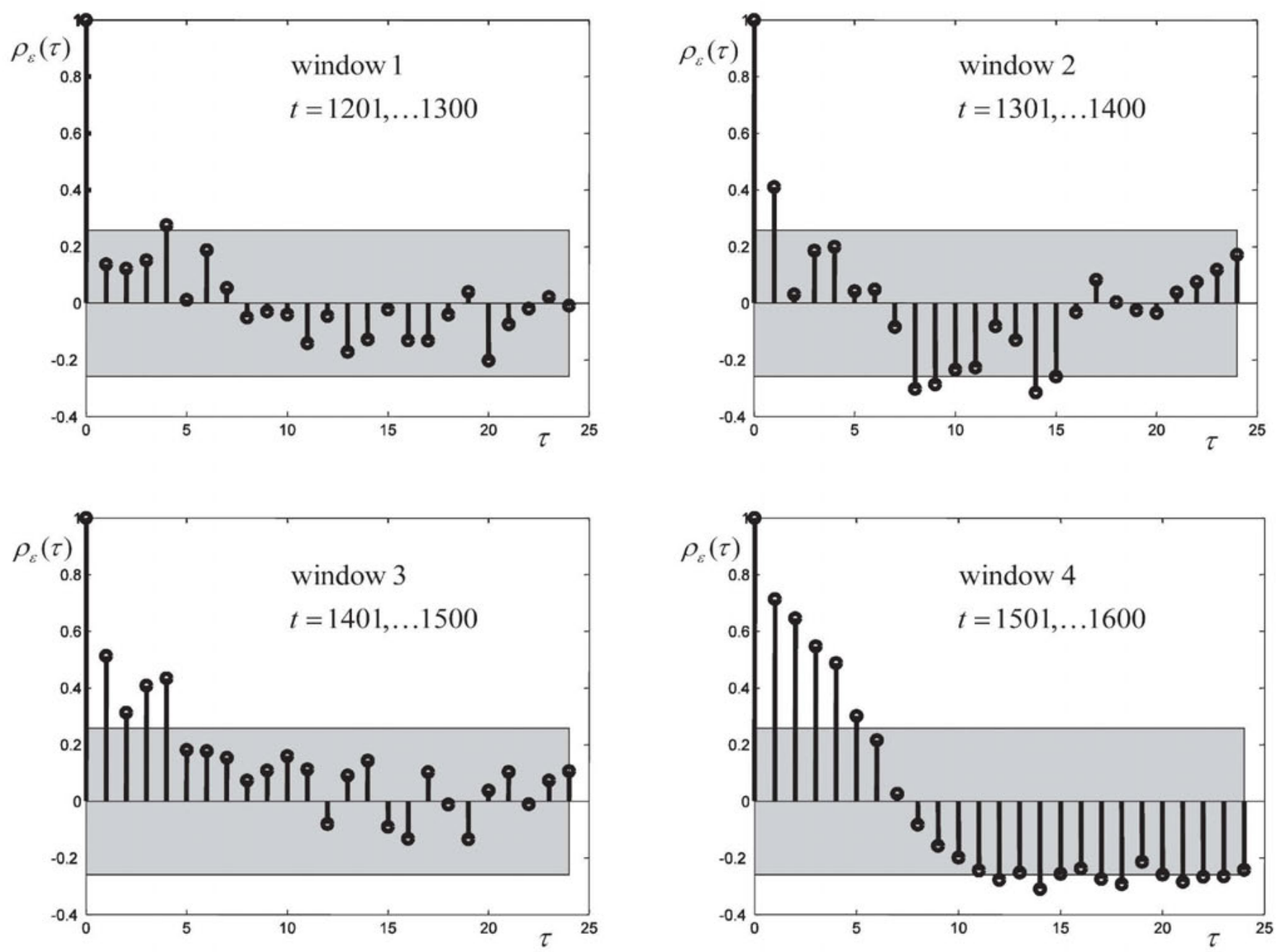

Figure 10. Whiteness test for each time window in the transition segment.

Figura 10. Test de aleatoriedad para cada ventana temporal en el segmento de transición.

achieved for each time window. The results are shown in Figure 10.

As is clear, the whiteness test is passed in just the first time window (though the values of $\rho_{\varepsilon}(\tau)$ present a suspicious regularity). The whiteness test is not passed in the other time windows, and this becomes clearer and clearer as the windows get closer to the earthquake phase.

\section{Conclusions}

The results of the Analysis of the transition phase via fault detection techniques section show that, in the collected data, it is possible to discern the transition phase from the normal seismic activity phase about 200-300 seconds before the beginning of the earth- quake phase. This is achieved by looking at the degradation of the prediction capabilities of the model identified during the normal seismic activity phase over the transition phase segment. In particular, a whiteness test for the prediction error has been used to this purpose.

Clearly, the main limitation of this analysis is that it is carried out on data collected in a location far away from the earthquake epicenter, so that earthquake waves are registered after distortion due to the propagation through the earth. This means that the phenomenon studied by means of the available data is quite different from that perceived in the proximity of the earthquake's epicentre, and thus the analysis here reported in no way allows us to say that earthquakes can be forecasted.

Nonetheless, we still believe that the achieved 
result is interesting and that it may open up some further developments in the study of earthquakes.

\section{Acknowledgements}

Paper supported by Ministero dell'Istruzione, dell'Unversità e della Ricerca (MIUR) and by CNRIEIIT.

\section{References}

Anderson, T.W. 1971. The statistical analysis of time series. Wiley, New York.

Bittanti, S. 2017. Model Identification and Data Analysis. To appear.

Box, G.P.E., Jenkins, G.M. , Reinsel, G.C., Ljung, G.M. 2016.
Time series analysis - forecasting and control. Wiley, Hoboken.

Brockwell, P.J., Davis, R.A. 2002. Introduction to times series and forecasting. Springer, New York.

Durbin, J. 1959. Efficient estimators of parameters in moving average models. Biometrica, 46, 306-316.

Hwang, I., Sungwan, K., Youdan, K., Seah, C.E. 2010. A Survey of Fault Detection, Isolation, and Reconfiguration Methods. IEEE Transactions on Control Systems Technology, 18, 636-653.

Grunwald, P.D. 2007. The minimum description length principle. MIT press, Boston.

Ljung, L. 1989. System identification - theory for the user. Prentice Hall, Upper Saddle River.

Rissanen, J. 1978. Modeling by shortest data description. Automatica, 15, 465-471.

Soderstrom, T. and Stoica, P. 1989. System Identification. Prentice-Hall, Englewood Cliffs.

Stoica, P. and Moses, R. 2005. Spectral analysis of signals. Prentice Hall, Upper Saddle River.

Recibido: septiembre 2016

Revisado: diciembre 2016

Aceptado: enero 2017

Publicado: septiembre 2018 